\title{
A JUSTIÇA KELSENIANA
}

\author{
Eduardo Carlos Bianca Bittar \\ Doutor pelo Departamento de Filosofia e Teoria Geral do Direito \\ da Faculdade de Direito da Universidade de São Paulo; \\ Professor de Filosofia do Direito, da Universidade São Marcos e \\ da Universidade Ibirapuera
}

\begin{abstract}
Resumo:
Trata-se de investigar alguns aspectos pontuais da teoria kelseniana da Justiça, sobretudo destacando-se a relação das pesquisas ligadas ao purismo metodológico com o relativismo da Justiça. Com este intuito é que se direcionam as pesquisas para a compreensão do justo e do injusto nesta concepção.
\end{abstract}

Resumé:

Il s'agit d'une recherche de quelques remarques ponctuelles de la théorie kelsenienne de la Justice, surtout en détacheant la relation entre le purisme méthodologique et le rélativisme de la Justice. C'est avec cette intention qu'on dirige les recherches pour la compréhension du juste et de l'injuste dans cette conception.

Unitermos: teoria kelseniana; purismo metodológico; justo e injusto.

Sumário:

1. O positivismo jurídico

2. A Ciência do Direito

3. A Justiça e o Direito

Conclusões

Bibliografia

1. O positivismo jurídico

Para que se possa compreender com todo rigor necessário o que Hans Kelsen pretende em sua teoria acerca do valor Justiça, é mister atravessar a longa 
planície de suas investigações propriamente jurídicas. Ou seja, para que se possa dizer algo sobre o Kelsen da Justiça é necessário passar anteriormente pelo esquadrinhamento de conceitos-chave e pontos nodais de desenvolvimento de sua Teoria do Direito. Isto parece conditio sine qua non para o avanço da reflexão. Porém, quando se faz uma pesquisa se debruçar por sobre o complexo sistema de idéias jurídicas de Kelsen, não se pode senão fazê-lo de modo instrumental, dentro das pretensões deste escrito; uma análise detida da teoria kelseniana do Direito demandaria esforços incontidos, que aqui se voltam somente para a compreensão do problema da Justiça. Assim, ao se propor que este texto se refira ao Kelsen da Teoria do Direito, estar-se-á a fazê-lo de modo instrumental. De qualquer forma feito isto, poder-se-á perceber a intrínseca relação mantida entre seu sistema de idéias acerca do Direito e acerca da Justiça.

Hans Kelsen, como pensador do Direito, se qualilica dentro do diversificado movimento a que se costuma chamar de positivismo jurídico. A importância de situá-lo neste movimento está em localizar seu pensamento, suas principais fontes de influência e compreender suas pretensões teóricas. Neste sentido, há teóricos do positivismo que diferem em absoluto da postura kelseniana, o que motivou a que se mencionasse a teoria do filósofo vienense de positivismo normativista. ${ }^{1}$

Reflexo do positivismo científico do séc. XIX, ${ }^{2}$ o positivismo jurídico, ${ }^{3}$ como movimento de pensamento antagônico a qualquer teoria naturalista, metafísica, sociológica, histórica, antropológica... adentrou de tal forma nos meandros jurídicos que suas concepções se tornaram estudo indispensável e obrigatório para a melhor compreensão lógico-sistemática do Direito. Sua contribuição é notória no sentido de que fornece uma dimensão integrada e científica do Direito, porém, a metodologia do

1. O leque extenso de autores positivistas não permitiria que se estivesse a estudá-los seqüencialmente sem comprometimento dos fins deste estudo, de modo que se pode remeter o leitor à seguinte obra, mais extensa sobre o assunto: Grzegorczyk, Christophe; Michaut, Françoise; Troper, Michel (sous a direction de). Le positivisme juridique. Paris; Bruxelles: CNRS; Université Paris X; LGDJ; Story scientia, 1992.

2. "Il est généralement adınis que la théorie de Kelsen est radicalement positiviste, et ceci dans plusieurs sens de ce terme. Tout d'abord, elle l'est sur le plan philosophique: les liens qui unissaient Kelsen aux penseurs néo-positivistes groupés dans le Wiener Kreiss se manifestent dans son approche de la connaissance en tant que valeur en êlle-mêne. Ceci explique d'ailleurs le refus catégorique que le maître austrichien opposait à toute forme de 'métaphysique' comme stérile sur le plan cognitif" (Grzegorczyk, Michaut, Troper, Le positivisme juridique, 1992, p. 56).

3. "A pureza metodológica perseguida por Kelsen baseia-se na ausência de juízos de valor, de que acabamos de falar, e na unidade sistemática da ciência: volta-se, portanto, para uma nova noção de ciência fundada em pressupostos filosóficos da escola neokantiana" (Mario Losano, na Introdução em O problema da Justiça, p. XIII). 
positivismo jurídico identifica que o que não pode ser provado racionalmente não pode ser conhecido; sem dúvida nenhuma, retira os fundamentos e as fïnalidades, contentando-se com o que ictu oculi satisfaz às exigências da observação e da experimentação, daí sua restrição ao posto (positum ius positivum). ${ }^{4}$

Com os pilares teóricos fixados no método positivista é que Hans Kelsen (Teoria Pura do Direito) procurou delinear uma Ciência do Direito desprovida de qualquer outra influência que lhe fosse externa. Assim alhear o fenômeno jurídico de contaminações exteriores à sua ontologia seria conferir-lhe cientificidade. Neste sentido, o isolamento do método jurídico seria a chave para autonomia do Direito como Ciência. Desta forma, através das ambições de sua teoria, ter-se-ia uma descrição do Direito que correspondesse apenas a uma descrição pura do Direito.

As categorias do ser (Sein) e do dever-ser (Sollen) são os pólos com os quais lida Hans Kelsen para distinguir realidade e Direito, que caminham em flagrante dissintonia, em sua teoria. Mais precisamente, é com a quebra da relação ser/dever-ser que pretende Hans Kelsen operar para diferir o que é jurídico (fenômeno jurídico puro) do que é não-jurídico (cultural, sociológico, antropológico, ético, metafísico, religioso...). A Teoria Pura do Direito se propõe a uma análise estrutural de seu objeto, e, portanto, expurga de seu interior Justiça, sociologia, origens históricas, ordens sociais determinadas... A ela não se defere a tarefa de empreender todo este estudo, mas sim de empreender uma sistematização estrutural do que é jurídico, propriamente dito. ${ }^{5}$

Ser e dever-ser diferem entre si na mesma medida em que ciências sociais (humanas) diferem das ciências naturais (físico-matemáticas). Esta diferenciação repousa na distinção provocada pelos termos causalidade e imputação e suas conseqüências lógico-teóricas." De fato, condição e conseqüência se ligam pela imputação de uma sanção a um comportamento, na esfera do Direito; neste sentido, a sanção pode ser, como pode não ser aplicada. ${ }^{7}$ Causa e efeito, estudadas pelas ciências

4. "A sua Teoria Pura do Direito constitui a mais grandiosa tentativa de fundamentação da Ciência do Direito como ciência - mantendo-se embora sob império do conceito positivista desta última e sofrendo das respectivas limitações - que o nosso século veio até hoje a conhecer" (Larenz, Metodologia da Ciência do Direito. Trad. José Lamego. Fundação Calouste Gulbenkian. Lisboa. 1989.p. 82).

5. Kelsen, O que é Justiça! A justiça, o Direito e a política no espelho da ciência, 1998, pp. 291-293.

6. "Condição e conseqüência estão ligadas não segundo o princípio de causalidade, mas segundo o princípio de imputação" (Kelsen, $O$ que é Justiça? A Justiş a, o Direito e a política no espellıo da ciência, 1998, p. 327).

7. "O princípio da imputação afirma: se A existe, B deve existir" (Kelsen, O que é Justiça!" A Justi(‘ı. " Direito e a política no espelho da ciência, 1998, p. 331 ). 
naturais, se comportam com regularidade, e, então, o que é causa provoca necessariamente o efeito respectivo.

Tendo em vista estas considerações, o conceito de responsabilidade (zurechnungsfähig) passa a significar que a sanção pode ser imposta a um sujeito (sujeito capaz de direito e de fato); o conceito de irresponsabilidade (unzurechnungsfähig) passa a significar que a sanção não pode ser imposta a um sujeito (louco, doente mental, menor, incapaz por surdez...). Assim, causalidade (ciências naturais) e imputação (ciências sociais) passam a ser as grandes categorias a partir das quais Kelsen estrutura seu pensamento. Como derivação desta distinção decorrem inúmeras conseqüências teóricas, sobretudo aquelas ligadas à distinção entre ser e dever-ser, isolados e neutralizados laboratorial e aritmeticamente. O dever-ser jurídico não se enraiza em qualquer fato social, histórico; não é condicionado por nada o que possa perverter sua natureza de puro dever-ser; Kelsen desenraiza o Direito de qualquer origem fenomênica, a título de compreendê-lo autonomamente em sua mecânica.

Então, a atitude do jurista, segundo Kelsen, deve consistir num partir da norma jurídica dada para chegar à própria norma jurídica dada. Esta postura é nitidamente contrária à que procura questionar os valores que antecederam à elaboração da norma jurídica (aqui se procede raciocinando a partir da norma retrospectivamente), ou ao que seria possível de se conceber após a elaboração da norma jurídica (aqui se procede raciocinando a partir da norma prospectivamente). Para o positivismo kelseniano, a norma jưrídico é o alfa (a) e o ômega (W) do sistema normativo, ou seja, o princípio e o fim de todo o sistema.

Inclusive, em sua teoria, a noção de Estado se identifica com a noção de Direito, sendo que este consiste no ordenamento de normas jurídicas coercitivas da conduta. Assim, todo Estado é um ordenamento jurídico, mas nem toda ordem jurídica é um Estado. ${ }^{8}$ Apenas a ordem jurídica centralizada pode ser dita Estado.

Se a norma jurídica encontra posição nuclear em seu sistema teórico, o conceito-chave, e de maior importância de sua teoria, é o conceito de validade. Esta consiste na existência da norma jurídica, ou seja, em sua entrada regular dentro de um sistema jurídico, observando-se a forma, o rito, o momento, o modo, a hierarquia, a estrutura, a lógica de produção normativa prevista num dado ordenamento jurídico.

8. "Se o Estado é uma comunidade, é uına comunidade jurídica" (Kelsen, O que é Justiça?' A Justiçı, "Direito e a política no expelho da ciência, 1998, p. 290). Mas, "nem toda ordem jurídica é um Estado" (Kelsen, O que é Justiça! A Justiça, o Direito e a política no espello da ciência, 1998, p. 290). 
Ser válida, não significa o mesmo que ser verdadeira ou falsa, mas sim estar de acordo com procedimentos formais de criação normativa previstos por um determinado ordenamento jurídico. A validade não submete a norma ao juízo do certo ou do errado, mas sim ao juízo jurídico, propriamente dito, ou seja, ao juízo da existência ou-não (pertinência a um sistema formal) para um determinado ordenamento jurídico."

Do conceito de validade ${ }^{10}$ é que se pode partir para o conhecimento do fundamento de todo o ordenamento jurídico: a norma fundamental (Grundnorm). De fato, na cascata das recíprocas relações de validade entre as normas é que reside a chave para a dissecação do conceito de norma fundamental, que nada mais é que o fundamento último de validade de todo um sistema jurídico. O sistema jurídico, para Kelsen, é unitário, orgânico, lechado, completo e auto-suficiente; nele nada falta para seu aperfeiçoamento; normas hierarquicamente inferiores buscam seu fundamento de validade em normas hierarquicamente superiores. O ordenamento jurídico se resume a este complexo emaranhado de relações normativas. Qualquer abertura para fatores cxtrajurídicos comprometeria sua rigidez e completude, de modo que a norma lundamental desempenha este papel importante de fechamento do sistema normativo escalonado.

Ao problema de onde estaria o ponto de apoio de todo o sistema jurídico a resposta do positivismo kelseniano seria: numa cstrutura escalonada de normas, onde a última aparece como norma fundamental, ápice de uma pirâmide de relações normativas. Onde há hierarquia há interdependência entre normas, onde há interdependência a validade da norma inferior é extraída da norma superior, e assim até uına última norma, a norma fundamental. Esta não é a norma constitucional de um Estado (Constituição da Argentina, Constituição da França, Constituição do Brasil...), mas sim um pressuposto lógico do sistema, o cume da pirâmide escalonada de normas jurídicas. Ela não existe historicamente, e nem físicamente, mas é pressuposta logicamente. O estatuto teórico da norma fundamental (qual a sua natureza, a sua função,

9. "Uma importante diferença entre a verdade de um enunciado e a validade de uma norına consiste em que a verdade de um enunciado precisa ser verificável, quer isto dizer: ser verificável como verdadeiro ou falso. A validade de umna norma não é, porém, verificável" (Kelsen Teoria Geral da.s Normaı, 1986, p. 227).

10. "À pergunta: qual o objetivo da teoria pura do Direito? A resposta é unívoca: o objetivo da teoria pura do Direito é ser uma teoria da validade do Direito" (...) "Dizer que uma norma jurídica existe, significa, para Kelsen, dizer que ela é válida" (Mario Losano, na Introdução em O problema da Justiç, p. XVI). 
a razão de sua existência...) parece ser o maior problema para esta criação da teoria kelseniana."

Neste mesmo sentido é que se pode desenvolver esta questão com outras palavras. Para Kelsen, a Teoria do Direito possui dois juízos de valor: 1. valores de Direito, cujo parâmetro objetivo é a norma jurídica (lícito/ ilícito); 2 valores de justiça (justo/ injusto), cujo parâmetro subjetivo repousa em dados variáveis e indedutíveis (Justiça democrática, autoritária, nacionalista, demagógica...)..$^{12}$ Abordando-se os valores, pode-se dizer que a norma jurídica é a única segurança para a teoria do Direito; é ela o centro das investigações positivistas do Direito. Mas, ela não é a simples expressão da vontade do legislador, ${ }^{13}$ porque são muitas as possíveis vontades do legislador, o que torna a pesquisa da norma um dado fluído. A norma está sempre sujeita à interpretação, e é isto que permite que diversos sentidos jurídicos convivam num só ordenamento.

Assim, o conjunto das normas forma a ordem jurídica, que é um "sistema hierárquico de normas legais" 14 Toda ordem jurídica requer um regresso ad infinitum através das normas, até a norma fundamental (esta é "pressuposição do pensamento jurídico" 15 e não um dado histórico). Caso contrário, inexistente a norma fundamental, devem-se aceitar pressupostos metafísicos para a fundamentação da ordem jurídica (Deus, ordem universal, contrato social, Direito Natural...). O que se pode reconhecer é que existe um consentimento de todas as pessoas em aceitar a Constituição, ${ }^{16} \mathrm{e}$ é a partir deste simples dado que deve raciocinar o jurista; este é o "princípio da eficácia" kelseniano. Kelsen termina por afirmar que a "ciência jurídica não tem espaço para os juízos de Justiça" 17 mas somente para os juízos de Direito.

11. "Este princípio (da unidade) recebe em Kelsen o nome de norına fundamental, noção intuitivamente simples de ser percebida (se as normas do ordenamento compõem séries escalonadas, no escalão mais alto está a primeira norma da série, de onde todas as demais promanam) mas difícil de ser caracterizada (é a questão do seu estatuto teórico: é norma? É un ato ou fato de poder? É uma norma historicamente positivada ou uma espécie de princípio lógico que organiza o sistema?)" (Ferraz Jr., Introdus:ão (to estudo do Direito, 1994, $2^{\mathrm{a}}$ edição, p. 176).

12. Kelsen, O que é Justiça? A Justiça, oDireito e a política no espelho da ciência, 1998, pp. 203-224.

13. Kelsen, O que é Justiça? A Justiça, o Direito e a política no espellho da ciência, 1998, pp. 210-211.

14. Kelsen, O que é Justiça? A Justiça, o Direito e a política no espellho da ciência, 1998, p. 21.5.

15. Kelsen, O que é Justiça?' A Justiça, oDDireito e a politica no espelho da ciência, 1998, p. 218.

16. Kelsen, O que é Justiça? A Justiça, o Direito e a política no espelho da ciência, 1998, pp. 218-219.

17. Kelsen, O que é Justiça? A Justiça, o Direito e a política no espelho da ciência, 1998, p. 223. 
Numa doutrina, onde as normas têm total preponderância, até mesmo o fundamento do ordenamento vem definido como sendo uma norma, a norma fundamental, aquela que não remete a nenhuma outra. ${ }^{1 \times}$ Seu caráter é técnicognosiológico, e sua existência, puramente lógica." Assim, esta norma possui uma natureza puramente pensada, como forma de estancar o regresso ad infinitum do movimento cadenciado de busca do principium de validade de toda a estrutura piramidal do ordenamento jurídico; trata-se de uma fícção do pensamento, na busca de deterıninar logicamente um começo e um fim. ${ }^{20}$

Toda esta regência de normas por uma norma fundamental não exclui a possibilidade de o juiz agir aplicando e interpretando, ou seja, produzindo normas individuais. Também a atividade aplicativa é uma atividade que está às voltas com normas; interpretam-se normas gerais e criam-se normas individuais.

Neste passo, o sentido as normas jurídicas se alcança por meio da interpretação, mas esta não consiste em um processo de cognição de um sentido imanente, inefável, apriorístico, causado por leis morais ou naturais; trata-se simplesmente das possibilidades de sentido de um texto normativo, em sua literalidade. ${ }^{21}$

18. Sobre a norma fundaınental: "O próprio Kelsen, porém, deve admitir que essa não é uma norma jurídica no sentido definido pela teoria pura do Direito. Para esta, de fato, são jurídicas apenas as normas estatuídas pelo legislador; a norma fundamental, ao contrário, "deve ser pressuposta, porquanto não pode ser posta por uma autoridade, cuja competência deveria repousar sobre uma norma ainda mais elevada"

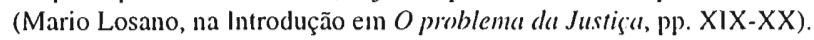

19. “A teoria pura do Direito, porém, é uma teoria jurídica monista. Segundo ela, só existe umn Direito: o Direito Positivo. A norma fundamental definida pela teoria pura do Direito não é um Direito diferente do Direito Positivo: ela apenas é o seu fundamento de validade, a conclição lógico-transcendental da sua validade, e, como tal, não tem nenhum caráter ético-político, mas apenas uın caráter teórico-gnosiológico" (Kelsen, O problema da Justiça, 1998, p. 117).

20. "A norma fundamental de uma ordem jurídica ou moral positivas - como evidente do que precedeu - não é positiva, mas meramente pensada, e isto significa uma norma fictícia, não o sentido de um real ato de vontade, mas sim de um ato meramente pensado. Como tal, ela é uma pura ou verdadeira ficção no sentido da vaihingeriana Filosofia de Como-Se, que é caracterizada pelo fato de que ela não somente contradiz a realidade, como tambéın é contraditória em si mesına. Pois a suposição de uıma norma fundamental de uma ordem religiosa: "Deve-se obedecer aos mandamentos de Deus, comno determina historicamente a primeira Constituição" - não contradiz apenas a realidade, porque não existe tal como sentido de um real ato de vontade; ela também é contraditória em si mesma, porque descreve a conferição de poder de uma suprema autoridade da Moral ou do Direito e com isto parte de uma autoridade - com certeza apenas fictícia - que está mais acima dessa autoridade" (Kelsen, Teoria Geral das Normas, 1986, pp. 328-329).

21. "O conteúdo das normas jurídicas não está, para ela, por qualquer modo pré-determinado pela razão, pela lei moral, ou por qualquer teleologia imanente, mas pode ser todo conteúdo que se queira" (Latenz, Metodologia da Ciência do Direito. 1989, p. 86); 
Neste esquema de idéias, interpretação e aplicação estão intimamente relacionadas, pois se trata de um processo cognitivo em direção à tỉxação do sentido da norma a ser aplicadir. Não há normas jurídicas que não passem pelo processo de interpretação. ${ }^{22} \mathrm{~A}$ interpretação, que é fundamentalmente a compreensão da literalidade das palavras da lei, ${ }^{23}$ no entanto, adverte Kelsen, não está ligada somente à aplicação do Direito, mas também aos processos cogniscitivos da Ciência do Direito; ao jurista teórico, como ao jurista prático, interessa a interpretação. Assim, para aquele, será a atividade do pensamento que identifica os possíveis sentidos jurídicos de uma norma jurídica, $\mathrm{c}$ para este, um ato de escolha de um destes possíveis sentidos por meio de um ato de vontade, a decisão. ${ }^{24}$ Há, portanto, duas formas de interpretação jurídica, para Kelsen. ${ }^{25}$

Quem aplica o Direito exerce a chamada interpretação autêntica do Direito. ${ }^{26}$ Autêntica aqui quer dizer que se trata do ato de interpretação copulado com o de aplicação; ${ }^{27}$ quando há esta fusão, então aquele que determina o sentido também decide, e aquele que decide também determina o sentido de forma concreta e final. É este ato e somente este ato que pode realmente pôr fim à cadeia das interpretações e discussões acerca do sentido de uma norma jurídica. Neste sentido, enquanto a Ciência do Direito polemiza (interpretação não-autêntica), o aplicador do Direito define (interpretação não-autêntica).

22. A interpretação será "de todas as normas jurídicas na medida em que hạjam de ser aplicadas" (Kelsen, Teoria pura do Direito, 1976, p. 463).

23. "Ele limita a interpretação jurídica à ınera interpretação verbal, à indicação das significações possíveis, de acordo com o sentido das palavras, entre as quais tem de escolher quem aplica a norma jurídica" (Larenz, Metodologia da Ciência do Direito, 1989, p. 95).

24. "A interpretação é, portanto, uma operação mental que acompanha o processo da aplicação do Direito no seu progredir de um escalão superior para um escalão inferior" (Kelsen, Teoric pura do Dircito, 1976, p. 463).

25. Mas, os cientistas do Direito também interpretam, mas sem aplicar, de modo que: "existem duas espécies de interpretação que devem ser distinguidas claramente unna da outra: a interpretação do Direito que não é realizada por um órgão jurídico mas por uma pessoa privada e, especialmente, pela ciência jurídica" (Kelsen, Teoria pura do Direito, 1976, p. 464).

26. "A interpretação feita pelo órgâo aplicador do Direito é sempre autêntica. Ela cria Direito" (Kelsen, Teoria murc do Direito, 1976, p. 470).

27. "A interpretação feita pelo órgão aplicador é autêntica, no sentido de que cria Direito, ainda que na sentença judicial só para o caso concreto. Coisa diversa se produz com a Ciência do Direito. Diversamente, a interpretação por um órgão jurídico não é produção de Direito, mas apenas 'fixaç̧ĩo puramente cognitiva do sentido de normas jurídicas' (RR, p. 352)" (Larenz, Metorlologia da ciềncia do Direito, 1989, p. 94). 
E isto tudo se deve ao fato de que a norma jurídica não possui somente um sentido, mas vários possíveis. ${ }^{2 \times}$ A Ciência do Direito procura somente identificar c descrever estes possíveis sentidos. ${ }^{29}$ As muitas possibilidades jurídicas lacultam muitas escolhas, e é nisto que reside a liberdade do juiz, ou seja, no poder de determinar qual dos sentidos é o mais adequado para o caso concreto ${ }^{30}$ Feita a escolha, no entanto, não há nada no Direito Positivo que permita dizer que esta escolla é melhor que aquela outra. ${ }^{31}$ Nenhum método torna esta escolha um ato objctivo c sensivelmente positivo a ponto de se tolher as possibilidades de escolha do juiz.

Este lineamentos são bastantes para se recordar a postura positivista (nãoaxiológica, não-política, não-ética...) e normativista (normas c validadc; norma fundamental e fundamento de validade; norma geral $\mathrm{c}$ individualização da norma) encontradas nos textos de Hans Kelsen.

\section{A Ciência do Direito}

Quando se trata de estudar o tema da ciência e do método kelsenianos, não se trata de dizer que sua teoria é uma teoria do direito puro (Direito como um fenômeno puro), mas sim que sua teoria é uma teoria pura do Direito (tcoria metodologicamente pura). ${ }^{32}$ Esta parece ser a primcira advertência necessária para que se possam evitar equívocos na leitura e interpretação das especulações kelsenianas; sua teoria representa por si só um purismo, porém não há cm Kelsen a pretensão de

28. E para a aplicação, tende-se dar conta de que "...o sentido verbal da norma não é unívoco, o órgão que tem de aplicar a norma encontra-se perante várias significações possíveis" (Kelsen, Tcorria pura do Direito. 1976, p. 465).

29. "A interpretação científica é pura determinação cogniscitiva do sentido das normas jurídicias" (Kelsen, Teoria pura do Direito, 1976, p. 472); "A interpretação jurídico-cientílica não pode fazer outra coisa senão estabelecer as possíveis significações de uma norma jurídica” (Kelsen, Teoria pura do Direito. 1976, p.472); A interpretação jurídico-científica tem de evitar, com o máximo cuidado, a ficção de çue uma norma jurídica apenas permite, sempre e em todos os casos, uma só interpretação: a interpretação correcta" (Kelsen, Teoria pura do Direito, 1976, p. 472).

30. "Se por interpretação se entende a fixação por via cogniscitiva do sentido do objecto a interpretar, o resultado de uma interpretação jurídica somente pode ser a fixação da moldura que representa o Direito a interpretar e, consequientemente, o conhecimento de várias possibilidades que dentro desta moldura existem" (Kelsen, Teoria pura do Direito, 1976, p. 467).

31. Afirma Kelsen: "Só que, de um ponto de vista orientado para o Direito Positivo, não há qualquer critério com base no qual uma das possibilidades inscritas na moldura do Direito a aplicar, possa ser preferida à outra. Não há absolutamente qualquer método - capaz de ser clarificado como de Direito Positivo - segundo o qual, das várias significações verbais de uma norma, apenas uma possa ser destacialla como correcta - desde que, naturalmente, se trate de várias significações possíveis: possíveis no confironto de todas as outras normas da lei ou da ordem jurídica" (Kelsen, Teoria pura do Direito, 1976, p. 468). 
alargar este purismo para que transforme o Direito, como acontecimento social, em fenômeno puro. Não se trata, portanto, de dizer que Kelsen afirmava a pureza do Direito em si; a pureza é atributo da ciência que quer construir.

Seus intentos científicos não se voltam para a descrição deste ou daquele ordenamento jurídico. Não se trata de detectar, ou descrever, este ou aquele Direito Positivo (belga, francês, alemão, inglês...), mas sim de se descrever cientificamentc o Direito, sem recorrer a pressupostos alheios à matéria jurídica e pertencentes a outras dimensões teóricas (Sociologia, Antropologia, Ética...). ${ }^{3.3}$ Em outras palavras, a Teoria Pura, ou seja, a Ciência do Direito para Kelsen, possui um objeto, ou seja, o Direito Positivo; é deste que deve se incumbir, sem pretender penetrar nas ambições da outras ciências geometricamente delimitadas.

Como já se disse, sua pretensão não é a de estudar, por meio desta ciência, os direitos positivos in concretu (Direito brasileiro, Direito islâmico, Direito uruguaio, Direito francês...), ou os possíveis ordenamentos vigentes num dado momento histórico, mas sim de estudar as estruturas com as quais se constrói o Direito Positivo, estruturas que seriam comuns a todos os sistemas, independentemente de sua localização geográfica ou de sua situação histórico-temporal. Descrever com a Teoria Pura o Direito é tratar das estruturas normativas (validade, vigência, promulgação, eficácia, sanção, revogação...).

Exclui-se de seu objeto, portanto, todo conteúdo de sociologia, de Justiça e seus respectivos juízos axiológicos... O que a Teoria Pura procura identificar como relevante para a pesquisa jurídica é o estudo da validade (existência de uma norma jurídica), a vigência (a produção de efeitos de uma norma jurídica), a eficcácia (condutas obedientes e observantes a uma norma jurídica). Toda pesquisa da Teoria Pura se resumc e se baseia no estudo da norma jurídica. ${ }^{34}$ Se assim ć, não se deve confundir seus

32. "Kelsen esclareceu repetidamente que a sua teoria é uma teoria pura do Direito Positivo e nĩo uma teoria do Direito puro, ou seja, de umna Direito desligado da realidade" (Mario Losano, na Introdução em $O$ problema da Justig (a, p. XV I).

33. "As idéias nucleares do sistema kelseniano são as seguintes: construção de uma teoria do Direito Positivo, mediante a pureza do método, isto é, despojar o Direito de seus resíduos sociológico, psicológico, histórico, político, afastando toda conotação teleológica - característica da Política, da Ética e da religião. Finalmente, elaborar um Direito puro, sem os seus condicionamentos externos" (Macedo, Históric do pensamento jurídico, 1982, p. 132).

34. "A Teoria Pura do Direito está apenas tirando uma conclusão óbvia quando formula a regra de Direito (usando o termo em sentido descritivo) como um juízo hipotético em que o delito surge como condição essencial e a sanção como a consequiência" (Kelsen, O que é Justiça!? A Justị̧a, o Direito e a política no espelho da ciência, 1998, p. 271). 
pressupostos metodológicos com os de outras escolas de pensamento do Direito que não possuam estas preocupações. ${ }^{35}$

A ciência, para Kelsen, deve, por exemplo, se diferenciar da política. $O$ político e o jurídico devem estar separados para que a ciência jurídica não se contamine com elementos de natureza política, correndo o risco de perder sua independência. ${ }^{36} \mathrm{~A}$ ciência não é ciência de fatos, de dados concretos, de acontecimentos, de atos sociais... ${ }^{37}$ a ciência, para Kelsen, é a ciência do dever-ser, ou seja, a ciência que procura descrever o funcionamento e o maquinismo das normas jurídicas. ${ }^{3 \%}$

Deve-se grifar, ainda, que a ciência, exercendo sua função de cognição de um objeto, não possui qualquer papel de autoridade, que decorre do exercício do poder de instituições sociais. Com isto se quer dizer que a Ciência do Direito, para Kelsen, não possui nenhum caráter vinculativo, pois a decisão judicial ou administrativa é que, evidentemente, determinará qual o sentido possível e admissível de uma norma jurídica a ser aplicado num caso concreto. A atividade da ciência consiste no produzir proposições jurídicas, descrevendo seu objeto; não está a ciência revestida de autoridade para decidir conteúdos de direito. ${ }^{39}$ Mais que isto, a Ciência (do Direito) interpreta, c

35. Distingue-se: da jurisprudência analítica e da jurisprudência sociológica. "Visto que a Teorii Pura do Direito limita-se à cognição do Direito Positivo e exclui dessa cognição a filosofia da Justiça, bem como a sociologia do Direito, sua orientação é em boa parte a mesma da chamada jurisprudência analítica, que teve sua orientação americana clássica com a obra de John Austin" (Kelsen, O que é Justi̧̧ı"? A Justiça, o Direito e a política no espelho da ciência, 1998, p. 267). 374.

36. Kelsen, O que é Justiça?" A Justiça, o Direito e a política no espelho da ciênciu, 1998, pp). 368/

37. "A ciência do Direito, segundo Kelsen, não tem a ver com a conduta efetiva do homem, mas só com o prescrito juridicamente. Não é, pois, uma ciência de factos, como a sociologia, mas una ciência de normas; o seu objecto não é o que é ou acontece, ınas sim um complexo de norınas" (Larenz, Metodolologia da Ciência do Direito, 1989, p. 82).

38. "A Teoria pura do Direito, muito ao invés, não se preocupa com o conteúdo, mas só com a estrutura lógica das normas jurídicas; verifica o sentido, a possibilidade e os limites de todo e qualquer enunciado jurídico (não de un certo enunciado jurídico), bem como a espécie e o modo de seu estabelecimento" (Larenz, Metodologia da ciência do Dircito, 1989, p. 83); ainda: "À Teoria pura do Direito o que interessa é a especificidade lógica e a autonomia metódica da Ciência do Direito" (Larenz, Metodologia da Ciência do Direito, 1989, p. 85).

39. "Se as proposiçōes por meio das quais a Ciência do Direito descreve seu objeto forem chamadas regras de Direito, devem ser distinguidas das normas jurídicas descritas por essa ciência. As primeiras são instrumentos da ciência jurílica, as segundas são funções da autoridade jurílica. Ao descrever o Dircito por meio de regras de Direito, a Ciência do Direito não exerce a função de autoridade social, que é uma função da vontade, mas a função da cognição" (Kelsen, O que é Jusstiça? A Justiç a, o Direito e a políticu no espelho da ciênciat, 1998, p. 362). 
desta interpretação derivam-se os múltiplos sentidos de uma norma jurídica; o papel da Ciência do Direito é descrever estes múltiplos sentidos.

\section{A Justiça e o Direito}

Quando se trata de avançar em direção à compreensão do tema da Justiça em Kelsen, se trata de avançar primeiramente no sentido de se compreender a relação mantida entre as normas jurídicas (objeto de estudo do Direito) e as normas morais (objeto de estudo da Ética). Assim, discutir sobre Justiça ć discutir sobre normas morais. Mas, para Kelsen, discutir sobre Justiça não é discutir sobre Direito, e vice-versa, c isto porque toda ordem jurídica é definida pelas normas jurídicas que possui. Assim, as normas jurídicas são estudadas pela Ciência do Direito, e são normas entre outras sociais, e estas últimas são morais, objeto de estudo da Ética como Ciência. Com esta delimitação já sc percebe que a(s) doutrina(s) da(s) Justiça(s) não é objeto de conhecimento do jurista, que deve estar afeito a compreender a mecânica das normas jurídicas.

O Direito possui a nota característica de poder ser moral (Direito justo), e de poder não-ser moral (Direito injusto); certamente, prefere-se o Direito moral ao imoral, porém não ć isto que retira validade de um determinado sistema jurídico. ${ }^{40} \mathrm{Um}$ Direito Positivo pode ser justo ou injusto, ou seja, um Direito Positivo sempre pode contrariar algum mandamento de Justiça, e nem por isso deixa de ser válido." O Direito não precisa respeitar um mínimo moral para ser definiclo c aceito como tal, pois a natureza do Direito, para ser garantida em sua construção, não requer nada além do valor jurídico. ${ }^{42}$ Mais uma vez deve-se afirmar que o que foi posto pelo legislador é norma jurídica se consignado internamente no ordenamento jurídico dentro dos moldes procedimentais c hierárquicos suficientes para tanto.

Assim, a conclusão acerca da relação cntre Direito c Moral não pode ser outra senão a de que:" "A exigência de uma separação entre Dircito e Moral, Dircito c Justiça, significa que a validade de uma ordem jurídica positiva é independente desta Moral Absoluta, única válida, da Moral por excelência, de a Moral" 43 Assim, ć válida

40. Kelsen, Teoria pura do Direito, 1976, p. 100.

41. "Um Direito Positivo pode ser justo ou injusto; a possibilidade de ser justo ou injusto é uma conseqüência essencial do fato de ser positivo" (Kelsen, $O$ que é Justişa? A Justişa, o Dircito e a política no expelho da ciência, 1998, p. 364).

42. Kelsen, Teoria pura do Direifo, 1976, p. 103.

43. Kelsen, Teoria pura do Direito, 1976, p. 104. 
a ordem jurídica ainda que contrarie os alicerces morais. ${ }^{4 t}$ Validade c Justiça de uma norma jurídica são juízos de valor diversos, portanto (uma norma pode ser válida e justa; válida e injusta; inválida e justa; inválida e injusta).

A discussão sobre a Justiça não se situa dentro das ambições da Teoria (Pura) do Direito, e isto porque Kelsen quer expurgar de seu interior a preocupaçĩo com o que é justo e o que é injusto. Discutir sobre a Justiça, para Kelsen, é tarefa da Ética, ciência que se ocupa de estudar não normas jurídicas, mas sim normas morais, $\mathrm{e}$ que, portanto, se incumbe da missão de detectar o certo e o errado, o justo c o injusto. E muitas são as formas com as quais se concebem o justo e o injusto, o que abeira cste estudo do terreno das investigações inconclusivas. ${ }^{45}$ Enfïm, o que é Justiçą?

Na mesma medida em que para a Ciência do Dircito é desinteressantc deter-se em investigações metodologicamente destinadas a outras ciências (Antropologia, Sociologia...), a Ética é considerada ciência autônoma sobre a qual não pode intervir a Ciência do Direito. A discussão sobre a Justiça não se situa dentro (las ambições da Teoria do Direito, portanto, c isto porque Kelsen quel expurgar de seu interior a preocupação com o que é justo c o que é injusto. Discutir sobre a Justiça, para Kelsen, é tarefa da Ética, ciência que sc incumbe de estudar não normas jurídicas, mas sim normas morais, c, portanto, incumbida da missão de detectar o certo c o errado, o justo c o injusto.

Isto não-significa dizer que Kelsen não csteja preocupado cm discutir o conceito de Justiça, c mesmo buscar uma concepção própria acerca deste valor. Isto quer dizer, pelo contrário, que toda discussão opinativa sobre valores possui um campo delimitado de estudo, o qual se costuma chamar de Ética. Aqui sim é lícito debater a Justiça ou a injustiça de um governo, de um regime, de determinadas leis... Por isso, Kelsen não se recusa a estudar o justo e o injusto; ambos possuem lugar em sua teoria, mas um lugar que não o solo da Teoria Pura do Direito; para esta somente o Direito Positivo deve ser objeto de preocupação. Daí dedicar-se, fora de sua obra Teoria pura do Direito, a extensas investigações sobre a Justiça, tendo publicado inúmeros artigos,

44. O Direito da Teorria Pura não pode ser por essência um fenômeno moral (Kelsen, Teoria purarı do Direits, 1976, p. 107).

45. "De fato, muitas e muitas normas de justiça, muito diversas e em parte contraditórias entre si, são pressupostas como válidas. Um tratamento científico do problema da Justiça deve partir destas normas de Justiça e por conseguinte das representações ou conceitos que os homens, no presente e no passado, efetivamente se fazem e fizeram daquilo que eles chamam justo, que eles designam como Justiça. A sua tarefa é analisar objetivamente as diversas normas que os homens consideram válidas quando valoram algo como justo" (Kelsen, O problema da Justiça, 1998, p. 16). 
e se detido com muito afinco no estudo de algumas teorias sobre a Justiça, como, por exemplo, a teoria platônica da Justiça, que se tornou obra coesa, publicada postumamente (O que é Justiça? A Justiça, o Direito e a política no espelho da ciência; O problema da Justiça; A ilusão da Justiça...).

Em O que é Justiça? A Justiça, o Direito e a política no espelho da ciência, as doutrinas sobre a Justiça são divididas $\mathrm{cm}$ racionalistas (Aristóteles, Kant, direito natural...) e metafísico-religiosas (Platão, Jesus...), e recebem um pormenorizado estudo. Já nos estudos preambulares da obra Kelsen declara sua opinião de que a Justiça não pode ser concebida de forma absoluta, e que, portanto, não pode ser entendido como lugar estanque, comum a todos os homens, de conteúdo inefável, tratando-se, pelo contrário, de algo extremamente mutável, variável. Para Kelsen, é este relativismo que deve induzir à tolerância, e a tolerância à aceitação. Sua teoria da Justiça se resume à isto.

A resposta cristã ao problema da Justiça consiste na obediência a qualquer Direito, pois todos os Direitos derivam de Deus. Neste caso, a fundamentação parte para uma concepção religiosa; seria nesta certeza religiosa que repousaria uma possível certeza científica. Porém, Kelsen adverte de que a lé não garante certeza à ciência. ${ }^{40}$

Desenvolve, então, em suas investigações, ${ }^{47}$ a idéia da Justiça das Sagradas Escritıras como uma Justiça extremamente contraditória. E isto não por outro motivo, senão porque a Palavra Revelada deveria ser a fonte não de idéias díspares, incompatíveis, conflitantes, mas sim de harmonia, integração, coesão, signos da imutabilidade da lição divina. Sua pesquisa, então se desenvolve no sentido de mostrar as incongruências textuais do textos sagrados, sobretudo aquelas existentes entre o Antigo e o Novo Testamento.

Trata-se de cstudar, com estas ambições, uma fonte religiosa sobre a Justiça (Bíblia), onde sua concepção vem estritamente fundada no poder da Revelação de Deus (atos e palavra); seus atos são suas intervenções na vida das pessoas, sua palavra, aquela dada nos Evangelhos. Este tipo de investigação deveria satisfazer no sentido de se identificar um conceito único e definitivo de Justiça (a Justiça como valor absoluto), ou seja, um sobre o qual se pudessc confiar toda fé, toda esperança, todo fulgor da alma, podendo-se, então, dormir o sono científico dos justos... Porém, existe uma franca contradição entre o Antigo Testamento (princípio da retaliação

46. Kelsen, O que é. Justiça?' A Iustị̧a, o Direito e a política no espellho da ciência, 1998, pp. 251-259.

47. Kelsen, O que é Justiça?' A Justị̧a, o Direito e a política no espellno da ciência, 1998, pp. 27-80. 
ensinado por Javé) c o Novo Testamento (com Cristo, a lei do amor c do perdão). É esta contradição que motiva à descrença num valor absoluto, perene, único, que induz ao relativismo. A diferença é muito acentuada, destaca Kelsen, entre os ensinamentos dados pela lei mosaica (Moisés e o Decálogo), a doutrina crística (Jesus Cristo e sua pregação) e os ensinos paulianos (Paulo de Tarso c suas Cartas c Exortações).

Estas variações não permitem lalar de uma unidade de conceitos ou de valores cristãos-judaicos absolutos dentro dos Evangelhos; muitas contradições conduzem a soluções de Justiça diversas, o que faz pressentir falta de homogeneidade na Palavra Revelada. É acentuado o fato de que o juízo lïnal provocará muitos males, e sua Justiça ocorrerá através da retribuição (penas c castigos; ranger de dentes). ${ }^{4 \star}$

Se, pelo contrário, a pesquisa se detiver sobre concepções fillosóficias, as mais evidentes e de maior influência na Antigüidade grega, talvez seja possível reter algo de definitivo acerca do conceito de Justiça. Porém, a pesquisa elaborada por Kclsen sobre as teorias platônica ${ }^{49}$ e aristotélica é exatamente uma pesquisa que demonstra o caráter insatisfatório das mesmas para responder à questão: o que é Justiça?

De fato, quanto à teoria platônica da Justiça, para Kelsen, reafïrma-se o aspecto metafísico e transcendente da teoria platônica, que operacionaliza scus conceitos a partir das categorias real/ideal; a análise debruça-se sobre os principais aspectos aprofundados em $A$ ilusão da Justiça. A Justiça, na teoria platônica, é uma virtude, e liga-se diretamente à virtude a idéia de conhecimento (só se erra por ignorância), de modo que a virtude é algo ensinável; ${ }^{50)}$ mas, se todo conhecimento somente pode ser dito como tal se se detiver nas Essências, c não nas aparências, então, a Justiça que se ensina é acerca do que É e não do que parece ser; entre Bem e Mal, a Justiça ensinável é algo que aponta para o Bem. ${ }^{51}$ Mas, o que é justo não pode ser objeto de clóxa, mas somente de epistéme, e esta não é senão o conhecimento por meio da dialética; a própria massa dos homens não está em acordo quanto ao que seja a Justiça. ${ }^{52}$

A crítica de Kelsen recai no fato de a teoria platônica estar exercendo

48. Kelsen. O que é Justiça? A Justi(a, o Direito e a politica no espellos da ciência, 1998, pp. 69-70.

49. Kelsen, O que é Justişa? A Justiça, o Direito e a política no espelho da ciência, 1998, pp. 81 - 107.

50. Kelsen, A ilusão da Justişa, 1995, pp. 142-152.

51. Kelsen. A ilusão da Justica. 1995, pp. 01-17.

52. Kelsen, A ilusäo da Justişa, 1995, p. 279. 
uma vontade de eticizar o mundo natural, ${ }^{53}$ como ocorre no Fédon, julgando-o entre Bem e Mal. Nesta concepção, tudo que é material é efêmero, e tudo que é só pode ser entendido como tal se inefável, transcendente. A justiça (humana, relativa, inconstante...) nada mais é que cópia da Justiça (Absoluta, Verdadeira, Real...), pois, instável e imperfeita, só pode ser algo que deriva do conlecimento instável e imperfeito que o homem possui da Verdade, da Realidade, do que É, de acordo com a teoria metafísica do conhecimento exposta no Mênon e no Fedro. ${ }^{54}$ Entre o Justo Absoluto, inalcançável de imediato, somente contemplável, c o Injusto Absoluto, existe o justo empírico, humano, realizável..$^{55}$

Em poucas palavras, extrai-se da doutrina que não se pode ser justo ou injusto somente para esta vida, pois se a alma preexiste ao corpo, é porque também subsiste à vida carnal, de modo que ao justo caberá o melhor e ao injusto o pior (doutrina órfico-pitagórica; dualismo escatológico); ${ }^{56}$ ao justo, a ilha dos bem-aventurados, ao injusto, o Tártaro; toda alma aparece nua diante de um Tribunal, que sentenciará os acertos e os erros, ${ }^{57}$ determinando o fim de cada qual no Além. ${ }^{5 x}$

Neste sentido, o Direito Positivo (Justiça relativa, imperfeita, realizável, humana...) deve ser obedecido, pois seu fundamento está na natureza e na

53. Kelsen, A ilusão da Justişa, 1995, pp. 189-192.

54. Kelsen, A ilusãu da Justiça, 1995, pp. 203-218.

55. Kelsen, A ilusãuo da Justiça, 1995, pp. 40-61.

56. O castigo corrige, emenda, ensina; é a única forma de correção do incorreto; também a intimidação metafísica (temeridade pelo futuro no Hades) é aliada da correção e educação das almas (pp). 305/310). Mais que tudo, a Justiça como retribuição (paga pelos males causados a homens e a deuses) no Além é a doutrina da pedagogia do agora, pois atemoriza pela possibilidade da sanção. O castigo que corrige vem baseado numa Lei de Talião (olho por olho dente por dente). O melhor à alma que se separa do corpo é nada dever a ninguém, pois aquele que algo dever, ainda que se esconda (Leis, 905), sob a Justiça encaminhada pela providência divina haverá de sucumbir. De fato, a retribuição é o modo de Justiça metafísica (República, 613) que ocorre desde o aqui e também no Além. O mito final da República ilustra a doutrina da paga no Além: as almas despidas apresentam-se ao tribunal, umas justas passam à direita de Deus (gozos), outras injustas à esquerda e para baixo de Deus (penas); as almas, neste ciclo de mil anos, permanecem indo e vindo, e suas penas nunca são eternas. Toda alına que transmigra tem Direito a escolher, diante das três moiras, a sorte que deseja cursar, dentro de vasto leque de opções, com profissões e posições sociais, levando-se em conta as aptidões que possui; logo em seguida submete-se a alma a beber a água do rio Ameles para o esquecimento. O próprio renascimento, neste sentido, significa a Justiça em funcionamento (Kelsen, A iluscīo da Justiça, 1995, pp. 31.5-323).

57. Seja no Górgias, seja nas Leis, 904, seja na República, a retribuição aparece como a forma providencial de justiça cósmica. Nas Leis, sobretudo, a ordem do mundo é dada pela Justiça retributiva (Leis 903). Esta é infalível (Kelsen, A ilusão da Justiça, 1995, pp. 325-327).

58. Kelsen, A ilusão da Justiça, 1995, pp. 300-304. 
transcendência da própria Justiça absoluta, esta inatingível, inalcançável, inexprimível; o Estado aí é mero instrumento para a realização da Justiça. ${ }^{59}$ A obediência, mesmo às leis iniqüas deve ser irrestrita, pois também Sócrates submeteu-se, feliz, à sentença condenatória que, injustamente, the fora imposta (Apologia de Sócrates); assim, o Direito Positivo vem justificado metafisicamente, e a legitimidade deste direito deriva deste direito natural irracional. ${ }^{(1)}$ De todo o esforço platônico não resta um conceito estável e sólido sobre o que seja a Justiça; mais ainda, a fluidez de sua metafísica transforma a Justiça num valor inefável, e, portanto, destituído de conteúdo material e humano.

Quanto à teoria aristotélica da Justiça, ${ }^{61}$ partindo de uma premissa equivocada, a de que Aristóteles é um racionalista, Kelsen interpreta o sistema de idéias sobre a justiça contida na Ética à Nicômaco como sendo um esquema matemáticogeométrico. Assim, a justiça dotada de igualdade e proporcionalidade, dividida em distributiva (geométrica), comutativa (aritmética)... seria nada mais que um esboço de matematização da justiça, esboço naturalmente, segundo Kelsen, fadado ao fracasso teórico.

Partindo da identificação do bem maior metafísico (Deus), causa incausada, procura-se identificar na investigação da Ética uma busca pelo que é o bem para o homem (felicidade). Residindo a felicidade na virtude, e sendo a Justiça uma virtude, nestes quadrantes é que se tecem considerações sobre a doutrina do meio termo (mesótes). Kelsen, quer declarar insuficiente remeter a definição da Justiça a uma fórmula vazia, ao "a cada um o seu" (segundo o mérito ou segundo o princípio da não-invasão do que é do outro); mais que isto, o que é meu, e o que é seu, para Kelsen não parece claro o suficiente para que sirva de parâmetro para definição.

A Justiça aristotélica aparece dividida em justo total (legitimidade), subdividido em justo natural e justo positivo, e justo particular, subdividido em justo

59. A divisão do trabalho é a regra de Justiça no Estado Ideal; três classes dividem-se emn três atividades (política; defesa; econoınia), não podendo haver interferência de uına classe na atividade da outra; a interferência representa a injustiça (Kelsen, A iluscĩo da Justiça, 1995, p. 462). Isto, pois, cada classe corresponde a uma parte da alma, e a alma racional, aliada à epitimética, deve governar. Onde o filósofo platônico governa não são necessárias leis, pois sua vontade é a vontade do Estado as leis somente aparecem como um paliativo, como unna alternativa viável para a falta de um verdadeiro homem sábio. Neste caso, as leis não devem e não podem ser desobedecidas eın hipótese alguma, como se afirma no Político. 300 (Kelsen, A ilusão da Justiça, 1995, pp. 498-50I e p. 503).

60. Kelsen, $A$ ilusão da Justiça, 1995, pp. 504-519.

61. Kelsen, O que é Justiça?' A Justiça, o Direito e a política no espellho da ciência, 1998, pp. 109-135. 
distributivo (igualdade geométrica) e justo comutativo (igualdade aritmética). Aqui estaria para Kelsen, a falha da teoria, que, preocupada com a identificação de espécies e subespécies, de tipos e classificações, teria perdido a noção de sua importância prática. Mais que isto, quando Aristóteles remete a discussão sobre a Justiça para a necessidade da amizade (entre amigos não há a necessidade de Justiça), Kelsen quer ver aí uma renúncia de Aristóteles à discussão do tema do qual se acercou: a Justiça. Porque, para Kelsen, Aristóteles teria deixado de definir o que é a justiça, remetendo o problema para a amizade.

Resposta alguma, muito menos, sobre o que seja a Justiça se pode encontrar, para Kelsen, nas teorias jusnaturalistas. ${ }^{62}$ Em qualquer Teoria do Direito Natural, qualquer que seja sua origem e sua proposta, sempre se estará procurando uma constância de valores imanentes na "natureza" No fundo, o que se quer dizer é que a resposta do Direito Natural é a seguinte: a natureza aparece como legisladora; ou melhor, a natureza é a norma fundamental de todo ordenamento jurídico. Como o conceito de "natureza" em si jâ é fluido, esta natureza pode ser: natureza humana; natureza biológica; natureza social; natureza racional. A ambigüidade e os retoques teóricos já começam aqui, demonstrando-se que o terreno do que seja o natural é em si fonte de discórdias entre seus próprios teóricos. A dificuldade avulta quando se procura identificar justiça e natureza, e por consequiência, Justiça e Direito, pois, o que ocorre é uma confusão imperdoável entre valor (dever-ser) e fato (causa/efeito). Desta forma, este tipo de abordagem recai invariavelmente na aceitação de um essencialismo dedutível e observâvel da natureza. Na avaliação de Kelsen, a demonstração, método próprio da ciência natural, é confundida com a avaliação, método próprio das ciências valorativas. $\mathrm{O}(\mathrm{s})$ jusnaturalismo(s), portanto, procedendo desta forma, não estaria(m) apto(s) a responder ao desafio do que seja a Justiça.

Enfim, quer-se dizer que as escolas e teorias sobre o justo e o injusto são muitas. ${ }^{63}$ Podem-se, pelo menos, alistar as seguintes teorias que partem de um pressuposto para encerrarem suas conclusões, a saber: 1 . O dar a cada um o seu (suum cuique tribuere); 2. a regra de ouro (Não faças aos outros o que não queres que façam a ti); 3. o imperativo categórico (Age sempre de tal modo que a máxima do teu agir possa por ti ser querida como lei universal); 4. o evitar o mal e o fazer o bem (bonum faciendum et male vitandum); 5. o costume como valor de Justiça social; 6. o meio-

62. Kelsen, O que é Justiça?' A Justiça, o Direito e a política no espelho da ciência, 1998, pp. 177-201. 63. Cfr., sobretudo, Kelsen, O problema da Justiģa, 1998. 
termo aristotélico (mesótes); 7. a retribuição; 8. a equivalência na prestação; 9 . o amor ao próximo; 10. o contrato social, a democracia liberal; 11 . a Justiça e a felicidade; 12. o jusnaturalismo da natureza, da razão...

Diante deste enorme desfile de escolas e doutrinas, a posição kelseniana é cética, negando preponderância a uma ou a outra. São plúrimas as formas de se compreender o que seja a Justiça; a resposta à questão fica em aberto, portanto. Assim, se todas estas teorias e concepções concorrem para uma resposta ao problema, a Justiça deve ser um valor inconstante, relativo, dissolúvel e mutável; é nisto que se resume a concepção kelseniana sobre o fenômeno.

Assim, o que ocorre é que este ceticismo leva Kelsen a afirmar que o terreno dos valores está destituído de qualquer constância; a existência de valores díspares é motivo de descrença para o filósofo da matematização e do rigorismo. ${ }^{64}$ Não admitindo existência à Justiça absoluta, que só pode se conceber a partir de pressupostos metafísicos e não-científicos, sua doutrina se abeira da noção de Justiça relativa, como resposta à questão do que seja a Justiça. Kelsen afïrma mesmo que a multiplicidade de valores sobre o justo e o injusto só pode reafirmar o fato de que todo Direito Positivo se entrechoque pelo menos com um destes. ${ }^{6.5}$

Justiça e injustiça nada têm a ver com validade de um determinado Direito Positivo; é esta a nota distintiva entre Direito e Ética. ${ }^{66}$ A validade de uma ordem jurídica não vem contrariada pelo simples fato de que o Direito se tenha construído contra a moral. ${ }^{17} \mathrm{O}$ que é válido prepondera sobre o que é justo, pois o que é válido

64. "Ao considerar o tema da justiça, Hans Kelsen aplica à teoria dos valores a mesına metodologia usada ao construir uma Teoria pura do Direito: no exame da justiça, assim como no do Direito, ele identifica cientificidade com não-valoração" (Mario Losano, na Introdução em O problema da Justiça, p. XXV).

65. "Admitindo-se a possibilidade de normas de Justiça diferentes e possivelmente contraditórias, no sentido, não de que duas normas de Justiça diferentes e possivelmente contraditórias possam ser tidas ao mesmo tempo como válidas, mas no sentido de que uma ou outra das duas normas de Justiça diferentes e possivelmente contraditórias pode ser tomada como válida, então o valor de Justiça apenas pode ser relativo; e, nesse caso, toda ordem jurídica positiva tem de entrar em contradição com qualquer uma destas normas de justiça. Por outro lado, cada ordem jurídica positiva pode corresponder a qualquer das várias normas de justiça constitutivas apenas de valores relativos, sem que esta correspondência possa ser tomada como o fundamento da sua validade" (Kelsen, O problema da Justiça, 1998, p. 69).

66. "Na independência da validade do Direito Positivo da relação que este tenha com uma norma de Justiça reside o essencial da distinção entre a doutrina do Direito Natural e o positivismo jurídico" (Kelsen, O problema da Justiça, 1998, p. 07).

67. A este respeito consulte-se Grzegorczyk, Michaut, Troper, Le positivisme juridique, 1992, p. 145. 
está de acordo com os modos de existência normativa de um dado ordenamento jurídico; o que é justo, por sua vez, está no plano das especulações, dos valores...e aceitar que o justo prepondera com relação ao válido é trocar o certum pelo dubium. ${ }^{6 \times}$ O que pode determinar o princípio de validade de todo um ordenamento é sua norma fundamental, pressuposto lógico-técnico do sistema, (") e não qualquer norma de Justiça. ${ }^{70}$ A norma fundamental basta para a clausura do ordenamento jurídico. Desvincular validade de Justiça, norma fundamental de Justiça... é a tarefa do positivismo kelseniano.

A questão da Justiça pode ser tratada por um detido estudo do que é e do que não é justo/ injusto, mas desta tarefa está isenta a Ciência do Direito, ao estilo kelseniano. O que há é que uma teoria sobre a Justiça responde por concepções acerca do justo e do injusto, e o que é justo e injusto nem sempre é claro e unânime. Porém, que há um justo e que este justo é um justo relativo, isto Kelsen admite."

\section{Conclusões}

O que há de se reter de toda esta reflexão é que a teoria da Justiça kelseniana, no fundo, e em verdade, é reflexo de sua postura jurídico-metodológica. $\mathrm{O}$ relativismo da Justiça, é o que se quer dizer, é, na teoria kelseniana, fruto do positivismo jurídico. Em síntese, as idéias de que a ciência pura é a ciência a-valorativa, a-histórica, a-ética... refletem o entendimento de que é possível, em ciências humanas, não-só extrair do fenômeno jurídico o que é não-jurídico, mas sim compreender o fenômeno jurídico como mecânica dotada de certeza, rigorismo e especifícidade; tudo isto é feito com sacrifício dos valores.

68. "Abstrair da validade de toda e qualquer norma de justiça, tanto cla validade daquela que está em contradição com uma norma jurídica positiva como daquela que está em harmonia com uma norma jurídica positiva, ou seja, adınitir que a validade de uma norına do Direito é independente da validade de uma norma de Justiça - o que significa que as duas normas não são consideradas como simultaneamente válidas - é justamente o princípio do positivisıno jurídico" (Kelsen, O problema da Justi̧̧a, 1998, p). 11).

69. "A norma fundamental determina somente o fundamento de validade, não o conteúdo de validade do Direito Positivo. Este fundamento de validade é completamente independente do conté́do de validade. A norma fundamental abandona a determinação do conteúdo do Direito Positivo ao processo determinado pela constituição, da criação positiva do Direito" (Kelsen, O problema da Justiça, 1998, p. 116).

70. "A norma fundamental de uma ordem jurídica não é de forma alguma uma norına de Justiça. Por isso, o Direito Positivo, isto é, uma ordem coativa criada pela via legislativa ou consuetudinária e globalmente eficaz, nunca pode estar em contradição com a sua norma fundamental, ao passo que esta mesma ordem pode muito bem estar em contradição com o Direito Natural, que se apresenta com a pretensão de ser o Direito justo" (Kelsen, O problema da Justi(̧, 1998, p. 117).

71. A este respeito consulte-se Grzegorczyk, Michaut, Troper, Le positivisme juridique, 1992, pp. 143-145. 
A autonomia do Direito, para Kelsen, só se alcança isolando o jurídico do não-jurídico. Isto quer dizer que o Direito, como ciência, deve significar um estudo lógico-estrutural seja da norma jurídica, seja do sistema jurídico de normas. Neste emaranhado de idéias, a própria interpretação se torna um ato, cogniscitivo (Ciência do Direito) ou não-cogniscitivo (jurisprudência), de definição dos possíveis sentidos da norma jurídica. A interpretação do juiz, ato prudencial, por natureza, para Kelsen, se transforma no ato de criação de uma norma individual. Qualquer avanço no sentido da eqüidade, dos princípios jurídicos, da analogia só são admitidos desde que autorizados por normas jurídicas.

Assim, a teoria da Justiça kelseniana só pode estar profundamente marcada por este conjunto de premissas. Assim, as mesmas prevenções do positivismo jurídico se transplantaram para o campo da discussão axiológica, dos valores. E estas perseguições se dão como forma de se ratificar a própria validade teórica da Ciência pura do Direito; a teoria dos valores induz ao relativismo, e este ao positivismo. E, assim, vice-versa.

São Paulo, dezembro de 2000. 
Bibliografia

ARENDT, Hannah. Entre o passado e o futuro. 2. edição. Trad. Mauro h:. Barbosa de Almeida. São Paulo: Editora Perspectiva, 1972.

A condição humana. Trad. Roberto Raposo. 4. edição. Rio de Janeiro:

Editora Forense Universitária, 1988.

ARIÈS, Philippe; DUBY, Georges. História da vida privada: da Primeira Guerra a nossos dias (sob a direção de Antoine Prost e Gérard Vincent). Trad. Denise Bottmann. São Paulo: Companhia das Letras, 1992. v. 5.

. História da vida privada: da Revolução Francesa à Primeira Guerra

(sob a direção de Michelle Perrot). Trad. Denise Bottmann e Bernardo Joffily. São Paulo: Companhia das Letras, 1991. v. 4.

BITTAR, Eduardo C. B. A evolução histórica da filosofia, in Revista da Faculdade de Direito da Universidade de São Paulo, v. 89, pp. 228-254, São Paulo, 1994.

. La reconstruction des droits humains d'après Celso Lafer: points de repère pour l'étude de la problématique de la rupture totalitaire, in Revista da Faculdade de Direito da Universidade de São Paulo, v. 90, pp. 399-410, São Paulo, 1995.

BOBBIO, Norberto. Nouvelles réflexions sur les normes primaires et secondaires, in La règle du Droit, Bruxelas, Ed. Perelman, 1971.

DEL VECCHIO, Giorgio. Lições de Filosofia do Direito. $5^{\text {a }}$ edição. Trad. de Antonio José Brandão. Coimbra: Armênio Amado, 1979.

DINIZ, Maria Helena. Compêndio de Introdução à Ciência do Direito. São Paulo: Saraiva, 1988.

DURANT, Will. A História da Filosofia. Trad. Luiz Carlos do Nascimento Silva. São Paulo: Nova Cultural, 1996.

FERRAZ JR., Tércio Sampaio. Introdução ao Estudo do Direito: técnica, decisão, dominação. 2" edição. São Paulo: Atlas, 1994.

FERRAZ JR., Tércio Sampaio. Teoria da norma juridica. $3^{\text {a }}$ edição. Rio de Janeiro: Editora Forense, 1997.

GRZEGORCZYK, Christophe; MICHAUT, Françoise; TROPER, Michel (sous a direction de). Le positivisme juridique. Paris; Bruxelles: CNRS; Université Paris X; LGDJ; Story scientia, 1992.

HABERMAS, Jürgen. O discurso filosófico da modernidade. Trad. de Ana Maria Bernardo, José Rui Meirelles Pereira, Manuel José Simões Loureiro, Maria Antonia 
Espadinha Soares, Maria Helena Rodrigues de Carvalho, Maria Leopoldina de Almeida, Sara Cabral Seruya. Lisboa: Dom Quixote, 1990.

HART, L.A. O conceito de Direito. Trad. de A. Ribeiro Mendes. Lisboa: Fundação Calouste Gulbenkian, 1986.

HUISMAN, Denis; VERGEZ, André. História dos filósofos ilustrada pelos textos. Trad. de Lélia de Almeida Gonzales. 2. edição. São Paulo: Freitas Bastos, s.d. JERPHAGNON, Lucien. História das grandes filosofias. Trad. Luís Eduardo de Lima Brandão. São Paulo: Martins Fontes, 1992.

KELSEN, Hans. A ilusão da Justiça. Trad. de Sérgio Tellaroli. São Paulo: Martins Fontes, 1995.

KELSEN, Hans. O problema da Justiça. Trad. de João Baptista Machado. $3^{\text {a }}$ edição. São Paulo: Martins Fontes, 1998.

KELSEN, Hans. O que é Justiça? A Justiça, o Direito e a politica no espelho da ciência. Trad. de Luís Carlos Borges. São Paulo: Martins Fontes, 1998.

KELSEN, Hans. Teoria Geral das Normas. Trad. de José Florentino Duarte. Porto Alegre: Sergio Antonio Fabris Editor, 1986.

KELSEN, Hans. Teoria pura do Direito. 4" edição. Trad. de João Baptista Machado. Coimbra: Armênio Amado Editor, 1976.

LARENZ, Karl. Metodologia da Ciência do Direito. Trad. José Lamego. Lisboa: Fundação Calouste Gulbenkian, 1989.

LYONS, David. As regras morais e a ética. Trad. de Luis A. Peluso. São Paulo: Papirus Editora, 1993.

MACEDO, Silvio de. História do pensamento jurídico. São Paulo: Liviaria Freitas Bastos, 1982.

POUND, Roscoe. Justiça conforme a lei. $2^{\mathrm{a}}$ edição. Trad. de E. Jacy Monteiro. São Paulo: IBRASA, 1976.

REALE, Miguel. Filosofia do Direito. 3"i edição. São Paulo: Saraiva, 1962. 